\title{
Suggested Applications of Musculoskeletal Ultrasound to Identify the Etiologies of Low Back Pain
}

\author{
Pardis Noormohammadpour ${ }^{1,2}$, Ali Ahmadzadeh Amiri (iD ${ }^{1,{ }^{*}}$ and Navid Moghadam (D) 1 \\ ${ }^{1}$ Sports Medicine Research Center, Neuroscience Institute, Tehran University of Medical Sciences, Tehran, Iran \\ ${ }^{2}$ Department of Sports and Exercise Medicine, School of Medicine, Tehran University of Medical Sciences, Tehran, Iran \\ "Corresponding author: Sports Medicine Research Center, Neuroscience Institute, Tehran University of Medical Sciences, Tehran, Iran. Email: ali_ahmdzdh@yahoo.com \\ Received 2021 July 11; Accepted 2022 January 11.
}

Keywords: Ultrasonography, Low Back Pain, Diagnosis.

\section{Background}

Low back pain (LBP) is the most common debilitating musculoskeletal disorder that influences approximately $80 \%$ of people one way or another in their lifetime $(1,2)$ and is also among the most common causes of absence from work $(3,4)$.

In recent years, there has been a worldwide increase in LBP incidence among various groups of the population (59). Therefore, a method is needed that can quickly and accurately determine the cause of this disorder. Plain radiographic X-ray, computerized tomography (CT), and magnetic resonance imaging (MRI) are widely used to unravel the cause of $\operatorname{LBP}(10,11)$; however, despite their many advantages, each modality has some limitations (12-14).

On the other hand, ultrasonography (US), as an inexpensive and safe method, has shown to be relatively effective in the diagnosis of musculoskeletal disorders $(15,16)$. Previously, we discussed the role of US in the diagnosis of various etiologies of LBP (17). Here we intend to briefly reintroduce the application of US as a diagnostic technique in various LBP etiologies and propound some novel suggestions for further studies.

\section{Previously Mentioned Application of Ultrasonogra- phy}

\subsection{Spinal Canal Diameter}

Based on the debates in the literature, we discussed that US could mainly measure spinal canal diameter with the oblique midsagittal (18) or transabdominal (19) techniques. Although the diameter of the spinal canal might be a predicting factor for suffering from LBP, due to operator-dependent factors, US measurement could not gain enough attention (20). However, we believe that more focused studies and appropriate techniques can be developed to solve its limitations.

\subsection{Paraspinal Muscles}

It was discussed that using rehabilitative US imaging in assessing paraspinal musculature by measuring their thickness, size (21), and echogenicity (22) has been shown to be acceptable for clinical practice (22). Given the profound role of paraspinal muscles in the development and prognosis of LBP and the availability of US in follow-ups after specialized training, we recommend a vaster acquisition of US in this field.

\subsection{Sacroiliac Joint Dysfunction}

Doppler imaging of vibrations is a diagnostic method that could be reliable and accurate in measuring the laxity of the sacroiliac joint $(23,24)$. We believe that more standard studies need to be done to thoroughly explore the benefits of using US in sacroiliac joint pathologies.

\subsection{Sacroiliac Joint Inflammation}

Despite the limitations, using color Doppler ultrasonography was revealed to be effective in the diagnosis and prognosis of sacroiliitis by visualizing the blood flow to the region $(25,26)$; whereas sacroiliac joint effusion could be detected using high-resolution US (27). Therefore, different modalities of US seem to be an effective alternative to other more expensive diagnostic techniques. 


\subsection{Spondylolisthesis}

It was shown that the measurement of vertebral dislocation using US should be sufficient for both diagnosis and follow-up of the patients with spondylolisthesis (28). Nevertheless, a lack of sufficient evidence at the moment limits the application of US in the complete management of spondylolisthesis.

\subsection{Transabdominal Muscles}

It appears that the transabdominal muscle dysfunction plays a profound part in the development and severity of LBP, and US proved to be a reliable modality to measure the transabdominal muscles thickness (29-31) especially in athletes (32). Also, it is easily available for the follow-ups after the training interventions; hence, we believe it might be the most effective modality in LBP rehabilitation via abdominal muscles training.

\section{New suggestions for the Application of Ultrasonog- raphy}

\subsection{Spondylolysis Diagnosis}

Pars interarticularis injury is one the most common etiologies of LBP, especially in young athletes. These lesions could be asymptomatic and later in adulthood become chronic and symptomatic (33). Spondylolysis is a nondisplaced fracture in pars interarticularis, which is caused by repeated stress to bones (34). Sport-related movements such as twisting, rotation, and extension augment the load on the spine and may lead to stress fractures (35). Studies showed that the majority of spondylolysis lesions could be found in asymptomatic patients; however, the most common complaint is either localized or diffused LBP (36).

There are various imaging modalities that may help clinicians in identifying the pars fracture lesions. Upon suspicion of an acute injury, it is recommended to perform an X-ray as the first diagnostic study. Then perform a scintigraphy or single-photon emission computed tomography (SPECT) is performed. In case of a positive SPECT, a computed tomography scan (CT) scan should be run to confirm the diagnosis in case of a positive SPECT. If SPECT comes negative, pars interarticularis injury has almost certainly been ruled out, and MRI could be used to discover other possible differential diagnoses (36). To our knowledge, there has been no report of using US in cases of spondylolysis. Considering that we could assess the continuity of the bone cortex, we suggest further standard studies in this field to investigate its feasibility and precision in this common condition.

\subsection{Disc Height Measurement}

Disc degeneration is believed to be one of the main etiologies behind discogenic chronic LBP, and with the increasing population age, this condition is becoming more prevalent $(37,38)$. Although imaging modalities such as MRI and CT scan are widely used to diagnose disc pathologies, they all have some considerable drawbacks, such as high cost. Therefore, with an increase in demand, a noninvasive, less expensive, and simple screening diagnostic method seems to be necessary. Many studies have shown that reduced disc height is associated with disc degeneration in the lumbar spine $(39,40)$; thus, we suggest US as an accessible alternative for disc height evaluation, especially when a discogenic condition is suspected.

\subsection{Facet Joint Inflammation Detection}

The degeneration of lumbar spine facet joints is one of the common conditions causing LBP (41-43). Current imaging modalities to diagnose facet joint lesions are $\mathrm{X}$ ray, computed tomography (CT), and magnetic resonance imaging (MRI). However, Shi et al. (44) studied the feasibility of using US in the diagnosis of lumbar facet joint degeneration and concluded that US could precisely show the facet joint structures; therefore, it is beneficial to diagnose the degeneration of facet joints of the lumbar spine by ultrasound. Furthermore, we presume that color Doppler technology can also be beneficial, especially in the early stages of the condition, as it has been proven that color doppler is a proper diagnostic tool in many inflammatory presentations.

\section{Conclusions}

To sum up, although there is a continuous improvement in the imaging technologies, US as an accessible, easy to use, and financially more reasonable modality has more potential in the diagnosis of different etiologies of LBP, especially in athletes; therefore, further investigations are needed to shed more light on the matter.

\section{Footnotes}

Authors' Contribution: All the authors have contributed effectively to this article based on the ICMJE standards.

Conflict of Interests: The authors declare that there is no conflict of interest.

Funding/Support: None declared by authors. 


\section{References}

1. Cassidy JD, Carroll LJ, Cote P. The Saskatchewan health and back pain survey. The prevalence of low back pain and related disability in Saskatchewan adults. Spine (Phila Pa 1976). 1998;23(17):1860-6. discussion 1867. doi: 10.1097/00007632-199809010-00012. [PubMed: 9762743].

2. Horvath G, Koroknai G, Acs B, Than P, Illes T. Prevalence of low back pain and lumbar spine degenerative disorders. Questionnaire survey and clinical-radiological analysis of a representative Hungarian population. Int Orthop. 2010;34(8):1245-9. doi: 10.1007/s00264-009-09200. [PubMed: 19997731]. [PubMed Central: PMC2989066].

3. Manchikanti L, Singh V, Falco FJ, Benyamin RM, Hirsch JA. Epidemiology of low back pain in adults. Neuromodulation. 2014;17 Suppl 2:3-10. doi: 10.1111/ner.12018. [PubMed: 25395111].

4. Wynne-Jones G, Cowen J, Jordan JL, Uthman O, Main CJ, Glozier N, et al. Absence from work and return to work in people with back pain: a systematic review and meta-analysis. Occup Environ Med. 2014;71(6):44856. doi: 10.1136/oemed-2013-101571. [PubMed: 24186944]. [PubMed Central: PMC4033140].

5. Urquhart DM, Bell R, Cicuttini FM, Cui J, Forbes A, Davis SR. Low back pain and disability in community-based women: prevalence and associated factors. Menopause. 2009;16(1):24-9. doi: 10.1097/gme.0b013e31817e5ce0. [PubMed: 18779757].

6. Pellise F, Balague F, Rajmil L, Cedraschi C, Aguirre M, Fontecha CG, et al. Prevalence of low back pain and its effect on health-related quality of life in adolescents. Arch Pediatr Adolesc Med. 2009;163(1):65-71. doi: 10.1001/archpediatrics.2008.512. [PubMed: 19124706].

7. Noormohammadpour P, Mansournia MA, Koohpayehzadeh J, Asgari F, Rostami M, Rafei A, et al. Prevalence of Chronic Neck Pain, Low Back Pain, and Knee Pain and Their Related Factors in CommunityDwelling Adults in Iran: A Population-based National Study. Clin J Pain. 2017;33(2):181-7. doi: 10.1097/AJP.0000000000000396. [PubMed: 27258995].

8. Freburger JK, Holmes GM, Agans RP, Jackman AM, Darter JD, Wallace AS, et al. The rising prevalence of chronic low back pain. Arch Intern Med. 2009;169(3):251-8. doi: 10.1001/archinternmed.2008.543. [PubMed: 19204216]. [PubMed Central: PMC4339077].

9. Louw QA, Morris LD, Grimmer-Somers K. The prevalence of low back pain in Africa: a systematic review. BMC Musculoskelet Disord. 2007;8:105. doi: 10.1186/1471-2474-8-105. [PubMed: 17976240]. [PubMed Central: PMC2198912].

10. Chou R, Qaseem A, Snow V, Casey D, Cross JJ, Shekelle P, et al. Diagnosis and treatment of low back pain: a joint clinical practice guideline from the American College of Physicians and the American Pain Society. Ann Intern Med. 2007;147(7):478-91. doi: 10.7326/0003-4819-147-7200710020-00006. [PubMed:17909209].

11. Carragee EJ, Hannibal M. Diagnostic evaluation of low back pain. Orthopedic Clinics. 2004;35(1):7-16.

12. Luo X, Pietrobon R, Sun SX, Liu GG, Hey L. Estimates and patterns of direct health care expenditures among individuals with back pain in the United States. Spine (Phila Pa 1976). 2004;29(1):79-86. doi: 10.1097/01.BRS.0000105527.13866.0F. [PubMed: 14699281].

13. Martin BI, Deyo RA, Mirza SK, Turner JA, Comstock BA, Holling worth W, et al. Expenditures and health status among adults with back and neck problems. JAMA. 2008;299(6):656-64. doi: 10.1001/jama.299.6.656. [PubMed: 18270354].

14. Ozcakar L, Tok F, De Muynck M, Vanderstraeten G. Musculoskeletal ultrasonography in physical and rehabilitation medicine.J Rehabil Med. 2012;44(4):310-8. doi: 10.2340/16501977-0959. [PubMed: 22402760].

15. Frost LR, Brown SH. Neuromuscular ultrasound imaging in low back pain patients with radiculopathy. Man Ther. 2016;21:83-8. doi: 10.1016/j.math.2015.05.003. [PubMed: 26037592].

16. Costa LO, Maher CG, Latimer J, Hodges PW, Shirley D. An investigation of the reproducibility of ultrasound measures of abdominal muscle activation in patients with chronic non-specific low back pain. Eur
Spine J. 2009;18(7):1059-65. doi: 10.1007/s00586-009-1018-5. [PubMed: 19415347]. [PubMed Central: PMC2899591].

17. Heidari P, Farahbakhsh F, Rostami M, Noormohammadpour P, Kordi $\mathrm{R}$. The role of ultrasound in diagnosis of the causes of low back pain: a review of the literature. Asian J Sports Med. 2015;6(1). e23803. doi: 10.5812/asjsm.23803. [PubMed: 25883773]. [PubMed Central: PMC4393543].

18. Porter RW, Wicks M, Ottewell D. Measurement of the spinal canal by diagnostic ultrasound. J Bone Joint Surg Br. 1978;60-B(4):481-4. doi: 10.1302/0301-620X.60B4.711793. [PubMed: 711793].

19. Tervonen O, Koivukangas J. Transabdominal ultrasound measurement of the lumbar spinal canal. Its value for evaluation of lumbar spinal stenosis. Spine (Phila Pa 1976). 1989;14(2):232-5. doi: 10.1097/00007632-198902000-00017. [PubMed: 2646739].

20. Porter RW, Bewley B. A ten-year prospective study of vertebral canal size as a predictor of back pain. Spine (Phila Pa 1976).1994;19(2):173-5. doi: 10.1097/00007632-199401001-00010. [PubMed: 8153826].

21. Wallwork TL, Stanton WR, Freke M, Hides JA. The effect of chronic low back pain on size and contraction of the lumbar multifidus muscle. Man Ther. 2009;14(5):496-500. doi: 10.1016/j.math.2008.09.006. [PubMed: 19027343].

22. Hides JA, Stokes MJ, Saide M, Jull GA, Cooper DH. Evidence of lumbar multifidus muscle wasting ipsilateral to symptoms in patients with acute/subacute low back pain. Spine (Phila Pa 1976). 1994;19(2):165-72. doi: 10.1097/00007632-199401001-00009. [PubMed: 8153825].

23. Muzaffer Buyruk H, Snijders CJ, Vleeming A, Laméris JS, Holland WP, Stam HJ. The measurements of sacroiliac joint stiffness with colour Doppler imaging: A study on healthy subjects. Eur J Radiol. 1995;21(2):117-21. doi: 10.1016/0720-048x(95)00716-4.

24. Damen Lé, Stijnen T, Roebroeck ME, Snijders CJ, Stam HJ. Reliability of sacroiliac joint laxity measurement with Doppler imaging of vibrations. Ultrasound Med Biol. 2002;28(4):407-14. doi: 10.1016/s03015629(02)00491-x.

25. Arslan H, Sakarya ME, Adak B, Unal O, Sayarlioglu M. Duplex and color Doppler sonographic findings in active sacroiliitis. $A J R$ Am J Roentgenol. 1999;173(3):677-80. doi: 10.2214/ajr.173.3.10470902. [PubMed: 10470902].

26. Klauser A, Halpern EJ, Frauscher F, Gvozdic D, Duftner C, Springer P, et al. Inflammatory low back pain: high negative predictive value of contrast-enhanced color Doppler ultrasound in the detection of inflamed sacroiliac joints. Arthritis Rheum. 2005;53(3):440-4. doi: 10.1002/art.21161. [PubMed: 15934066].

27. Spadaro A, Iagnocco A, Baccano G, Ceccarelli F, Sabatini E, Valesini G. Sonographic-detected joint effusion compared with physical examination in the assessment of sacroiliac joints in spondyloarthritis. Ann Rheum Dis. 2009;68(10):1559-63. doi: 10.1136/ard.2008.093351. [PubMed: 18957488].

28. Cresswell AG. Responses of intra-abdominal pressure and abdominal muscle activity during dynamic trunk loading in man. Eur J Appl Physiol Occup Physiol. 1993;66(4):315-20. doi: 10.1007/BF00237775. [PubMed: 8495692].

29. Bunce SM, Moore AP, Hough AD. M-mode ultrasound: a reliable measure of transversus abdominis thickness? Clinical Biomechanics. 2002;17(4):315-7. doi: 10.1016/s0268-0033(02)00011-6.

30. Bunce SM, Hough AD, Moore AP. Measurement of abdominal muscle thickness using M-mode ultrasound imaging during functional activities. Manual Therapy. 2004;9(1):41-4. doi: 10.1016/s1356689x(03)00069-9.

31. Mangum LC, Henderson K, Murray KP, Saliba SA. Ultrasound Assessment of the Transverse Abdominis During Functional Movement. $J$ Ultrasound Med. 2018;37(5):1225-31. doi: 10.1002/jum.14466. [PubMed: 29076538].

32. Noormohammadpour P, Hosseini Khezri A, Linek P, Mansournia MA, Hassannejad A, Younesian A, et al. Comparison of Lateral Abdominal Muscle Thickness and Cross Sectional Area of Multifidus in Adoles- 
cent Soccer Players with and without Low Back Pain: A Case Control Study. Asian J Sports Med. 2016;7(4). e38318. doi: 10.5812/asjsm.38318. [PubMed: 28144414]. [PubMed Central: PMC5259683].

33. Gagnet P, Kern K, Andrews K, Elgafy H, Ebraheim N. Spondylolysis and spondylolisthesis: A review of the literature. J Orthop. 2018;15(2):4047. doi:10.1016/j.jor.2018.03.008. [PubMed: 29881164]. [PubMed Central: PMC5990218].

34. Zukotynski K, Curtis C, Grant FD, Micheli L, Treves ST. The value of SPECT in the detection of stress injury to the pars interarticularis in patients with low back pain. J Orthop Surg Res. 2010;5:13. doi: 10.1186/1749-799X-5-13. [PubMed: 20199678]. [PubMed Central: PMC2841113].

35. Kayser R, Mahlfeld K, Heyde CE, Grasshoff H, Mellerowicz H. Tight hamstring syndrome and extra- or intraspinal diseases in childhood: a multicenter study. Eur Spine J.2006;15(4):403-8. doi:10.1007/s00586005-0886-6. [PubMed: 15912349]. [PubMed Central: PMC3489324].

36. Standaert CJ, Herring SA. Spondylolysis: a critical review. Br J Sports Med. 2000;34(6):415-22. doi: 10.1136/bjsm.34.6.415. [PubMed: 11131228]. [PubMed Central: PMC1724260].

37. DePalma MJ, Ketchum JM, Saullo T. What is the source of chronic low back pain and does age play a role? Pain Med. 2011;12(2):224-33. doi: 10.1111/j.1526-4637.2010.01045.x. [PubMed: 21266006].

38. Verrills P, Nowesenitz G, Barnard A. Prevalence and Characteristics of Discogenic Pain in Tertiary Practice: 223 Consecutive Cases Utilizing Lumbar Discography. Pain Med. 2015;16(8):1490-9. doi: 10.1111/pme.12809. [PubMed: 26217926].
39. Kimura S, Steinbach GC, Watenpaugh DE, Hargens AR. Lumbar spine disc height and curvature responses to an axial load generated by a compression device compatible with magnetic resonance imaging. Spine (Phila Pa 1976). 2001;26(23):2596-600. doi: 10.1097/00007632200112010-00014. [PubMed: 11725241].

40. Hebelka H, Brisby H, Hansson T. Comparison between pain at discography and morphological disc changes at axial loaded MRI in patients with low back pain. Eur Spine J. 2014;23(10):2075-82. doi: 10.1007/s00586-014-3408-6. [PubMed: 24957259].

41. Kalichman L, Hunter DJ. Lumbar facet joint osteoarthritis: a review. Semin Arthritis Rheum. 2007;37(2):69-80. doi: 10.1016/j.semarthrit.2007.01.007. [PubMed:17379279].

42. Manchikanti L, Boswell MV, Singh V, Pampati V, Damron KS, Beyer CD. Prevalence of facet joint pain in chronic spinal pain of cervical, thoracic, and lumbar regions. BMC Musculoskelet Disord. 2004;5:15. doi: 10.1186/1471-2474-5-15. [PubMed: 15169547]. [PubMed Central: PMC441387].

43. Goode AP, Carey TS, Jordan JM. Low back pain and lumbar spine osteoarthritis: how are they related? Curr Rheumatol Rep. 2013;15(2):305. doi: 10.1007/s11926-012-0305-z. [PubMed: 23307577]. [PubMed Central: PMC3606549].

44. Shi W, Tian D, Liu D, Yin J, Huang Y. The comparison of measurement between ultrasound and computed tomography for abnormal degenerative facet joints: A STROBE-compliant article. Medicine (Baltimore). 2017;96(31). e7680. doi: 10.1097/MD.0000000000007680. [PubMed: 28767595]. [PubMed Central: PMC5626149]. 